\title{
AN ESSAY ON THE GLOSSOMATIC PROCESS OF COMMUNICATING COMMUNICATIONS AND OTHER WORDS JESSICA FOLEY
}

JESSICA FOLEY works as a writer and creative transdisciplinary researcher. She is currently an Irish Research Council Postdoctoral Fellow at Maynooth University (MUSSI) 2018-2020 where she is developing research exploring the functions of fiction in parsing 'Smart Cities' and 'Internet of Things'. She is also a co-founding member of the Orthogonal Methods Group at CONNECT, the Science Foundation Ireland Centre for Future Networks and Communications. The Orthogonal Methods Group are unique in this context, bringing creative arts practices, critical pedagogy, feminist STS and new materialisms, new media scholarship and anthropology into critical conversation with science and technology research and industry.

During her PhD research at CTVR/CONNECT, Trinity College Dublin, Jessica pioneered a research-creation method called Engineering Fictions with engineering researchers and artists. Since 2013 Engineering Fictions, along with its twin Stranger Fictions (2018), has become a methodology that embraces the power of fiction and writing to foster and exercise creativity, honesty, diversity and ethical courage in Science and Technology research and industry.

Working contingently with people and contexts, materials and texts from across the worlds of contemporary art and design, education and engineering, Jessica's work focuses on opening up possibilities for embodied criticality and creative thinking and practices in ways that can support processes of change, healthy relations of difference and the enlargement of generosity and community.

Jessica's transdisciplinary practice is informed by her education in Graphic Design (B.Des. LSAD), Art and Design Education (H.Dip. LSAD), Contemporary Art (MA Art in the Contemporary World, NCAD) and Telecommunications Engineering (PhD. CTVR/TCD). 
Writing in the first person, my voice strains, sore and tight. For such a long time, I have aped the voice and academic writing style of Engineering, cloaking myself amongst the procedural trappings of the third person technical writer, the voice of the 'modest witness'. ${ }^{\text {. During my doctoral }}$ research, I sought to inhabit a challenge facing a telecommunications research centre, that of engendering critical and self-reflective communication in engineering research. My doctoral research was complicated.

Working in between scientific and artistic epistemologies, I was motivated by the idea that it was possible to create conditions for generous and generative communication in between disciplines like Engineering, Architecture and Contemporary Art. I wanted to gain insights on what communication could be in relation to this task, taking into consideration things like embodiment, sociality, academic conventions and the occupational politics of engineering as a profession. I called this process 'inreach', a critical and creative counterpoint to education and outreach practises in science and technology research. Inreach meant thinking with words, ideas, materials and histories of communication and then choreographing conversational experiments to generate critique within the context of engineering research, specifically, the Centre for Telecommunications ValueChain Research (CTVR) at Trinity College Dublin. ${ }^{2}$

In the process of 'writing-up' these conversational experiments, I surreptitiously lost my voice to the third person; the examination system insisted that I inhabit the passive voice of technical writing. If you look at the table of contents in my doctoral thesis, it has the appearance (organizationally) of an engineering thesis; every chapter broken down, as if procedurally, into numbered sections and subsections. And if you read the text, you will hardly hear my voice at all, except maybe in the footnotes, or muffled behind the third-person narrator of the research. As a result, I have not really used my voice in years. The thesis was written and defended... Pardon me, I mean to say: I wrote my thesis, I defended it, and I graduated with a Ph.D. in December 20I6. The following spring, I went to Vienna, to consult with labyrinths and statues and architectural philosophers at the ATTP. I went to Vienna to echo against European epistemologies and to listen to myself thinking out loud.

\section{INTRODUCTION}

Language is a central theme of the research discussed in this report, in particular the power of words to shape and orient research practises,

I Steven Shapin and Simon Schaffer, Leviathan and the Air-Pump: Hobbes, Boyle and the Experimental Life. (Princeton and Surrey: Princeton University Press, 1985); Carolyn R. Miller, 'A Humanistic Rationale for Technical Writing', College English, 40.6 (1979), 6ro-6r7; Donna Haraway, 'Situated Knowledges: The Science Question in Feminism and the Privilege of Partial Perspectives', Feminist Studies, I4.3 (I988), 575-599.

2 https://ctvr.ie/ [Accessed 31.10.18] 
attitudes and cultures in science and technology contexts. In our time, this theme surfaces urgently out of masses of alphanumerical data generated by pervasive networked radio-computing technologies. From city dashboards to everyday search queries on internet web browsers, in a digital world words have become instruments of political and economic power. Pip Thornton's work highlights this in her multifaceted and poetic critique of Google AdWords as a mode of linguistic capitalism: “... in an age of digital capitalism and big tech monopolies, words have become commodities that gain economic value the more and the faster they circulate through digital spaces." 3 The AdWords platform monetizes the words that browsers search via Google, generating the bulk of the company's wealth. ${ }^{4}$ Thornton argues that Google's AdWords platform effectively "strip[s] narrative context from the words we use while loading them with dissonant capital ... The text of e-mails, blogs, news, search queries, and literature is all in some way generating capital for one private, opaque, and ultimately unchallengable company."

The decontextualisation and subsequent commodification of words are foreshadowed in the work of Uwe Poerksen, whose critique of Plastic Words in the I980s expounded on transformations in vernacular language and the consequences of such changes, at a time when society was becoming increasingly 'scientized' and 'technologized,' or as we might say today, 'datafied' and 'digitized'. Plastic Words, Poerksen argues, are 'connotative stereotypes' that emerge out of an everyday mingling of science and technology language in society. ${ }^{6}$ Such words, Poerksen argues "tend to form sentences, even without verbs," for example: "Information is communication. Communication is exchange. Exchange is a relationship. A relationship is a process. Process means development. Development is a basic need. Basic needs are resources. Resources are a problem. Problems require service delivery. Service delivery systems are role systems. Role systems are partnership systems. Partnership systems require communication. Communication is a kind of energy exchange."7 J.M. van der Laan stresses the loss of ethical meaning in plastic language, arguing: "There is no link between an actual speaking human being and the words that are used." ${ }^{8}$ Thus, the

3 Pip Thornton, 'A Critique of Linguistic Capitalism: Provocation/Intervention', GeoHumanities, 2018, I-2I <https://doi.org/ro.108o/2373566X.2018.1486724>.

4 Frederic Kaplan, 'Linguistic Capitalism and Algorithmic Mediation', Representations, I27.I (2014), 57-63<https://doi.org/Io.1525/rep.2014.I27.I.57>; Thornton, 'A Critique of Linguistic Capitalism'.

5 Thornton, A Critique of Linguistic Capitalism: Provocation/Intervention'.

6 Uwe Poerksen, Plastic Words: The Tyranny of a Modular Language. (Philadelphia: Pennsylvania State University Press, 2004).

7 J. M. van der Laan, 'Plastic Words: Words Without Meaning', Bulletin of Science, Technology \& Society, 21.5 (2001), 349-53 <https://doi.org/ro.1177/027046760102100503>.

8 Poerksen, Plastic Words, 62; van der Laan, 'Plastic Words: Words Without Meaning', 35I. 
increasing prevalence of plastic words and the commodification of language more generally combine as a de-personalizing force in society.

These broad concerns resonate with and reflect many contemporary initiatives to create glossaries that specify and narrate the meaning of particular words and phrases, re-contextualizing them in a provisional and in relation to time, place and use. It is more and more common for researchers, artists and practitioners to provide glossaries as appendices to the materials and research they are working with and narrating for readers. One recent European initiative has been the New Materialisms Glossary developed as part of the COST Action IS $1307 .{ }^{9}$ Closer to hand, in my doctoral thesis I supplied a glossary in order to contextualize the specific ways in which I used words like 'occupation,' 'foiling' and 'communication' in the context of engineering research. ${ }^{\text {IO }}$ This glossary has since become one of the research-creation methods of the Orthogonal Methods Group ${ }^{\text {II }}$ at CONNECT, Trinity College Dublin.

Plastic words create tautological, self-referential or redundant effects that orchestrate impressions of narrative or, at least, orientation. The decontextualized quality of such words means they are deceptively functional and meaningful. But as Pip Thornton and others have argued, decontextualized and commoditized words have real effects on the way people live and experience the world..$^{12}$ And so too, the plastic words declaimed by Poerksen, van der Laan and many others before them (George Orwell for example) have a very real and powerful presence in the world. ${ }^{13}$ Arguably, the tendency towards such plastic, decontextualized and commoditized language generated the conditions that led to my work with the Centre for Telecommunications Value-Chain Research (CTVR). ${ }^{\mathrm{I}}$

The website featuring the New Materialisms Almanac was inaccessible at the time of writing. The address: www.newmaterialism.eu has been suspended. Details of the New Materialisms COST Action ISI307 can be found: https://www.cost.eu/actions/ IS $1307 / \#$ tabs|Name:overview [Accessed 2oth October 2018].

Io Jessica Foley, 'Inreach: A Choreographic Process of Transversality' (unpublished PhD in Engineering, Trinity College Dublin, 2016).

II The Orthogonal Methods Group is an interdisciplinary group of researchers based at CONNECT (formerly CTVR) interested in communications engineering, technology and society. Founded in 2015, the group emerged out of the collaborative research practice developed between myself and Prof. Linda Doyle during my doctoral research. Since then, the members have developed publications, exhibitions, public events and research residencies exploring the politics and ethics of technology in society. For further information visit: https://connectcentre.ie/omg [Accessed 2oth October 2018]

I2 Franco Berardi, The Uprising: On Poetry and Finance, Semiotext(e) Intervention Series, I4 (Los Angeles: Semiotext(e), 2012); Arjun Appadurai, Banking on Words: The Failure of Language in the Age of Derivative Finance (Chicago: The University of Chicago Press, 2016); Thornton, 'A Critique of Linguistic Capitalism'. George Orwell, Politics and the English Language (London: Horizon, I946); Poerksen. This research centre has since expanded to become CONNECT www.connectcentre.ie www.ctvr.ie [Accessed 2oth Oct 2018] 
The narrative and art-based doctoral research I developed through this CTVR took the plastic language of telecommunications engineering as a point-of-departure. From the everyday mingling of the language of art and telecommunications, I began improvising ways to creatively and to subtly critique the conditions and aspirations of technological research with engineering researchers. By inhabiting CTVR's question 'How do we Communicate Communications?', I created a writing workshop methodology called Engineering Fictions that structured a space and time for engineering researchers, artists and others to experience and reflect upon cultures and imaginaries of technological research.

This report offers a revised glossary of a number of words and phrases drawn from my narrative and practice-based research with CTVR. To this end, the objectives of this report are to contribute a working glossary of terms, stemming from my doctoral research practice, Inreach, that can contribute to this aim. In March 2017, while on a Short Term Scientific Mission with the ATTP, as part of the New Materialisms COST Action ISI307, I opened up a selection of words, phrases and practices from my doctoral research with the ATTP. Less the presentation of a glossary (i.e. a foreign, obscure or obsolete word which needs explanation), this approach reflects a glossomatic turn, a self-aware, social process of spontaneous thinking and emoting (drawing on the etymology of the suffix -matos, 'thinking, animated').

In that process, my glossomatics became subject to a process of enstrangement (discussed below), with the effect that my own apperception of them became enlarged and critically sharpened. In conversation with the ATTP, the poetry of my research came to the fore as meaningful to the formation of a more capacious literacy of communication(s).

\section{METHODS}

I travelled to Vienna from Dublin in early March 2017, to undertake a Short Term Scientific Mission as part of the New Materialisms COST Action ISI307. My intention was to explore the glossomatic method I had developed during my doctoral research in a different context and with a different research community. My hope was that the ATTP would act as a foil to my practice, helping to enstrange the conversational experiments and concepts I had been working with, i.e., Communicating Communications, inreach and Engineering Fictions. The concept of enstrangement (остранение, ostranenie) had been important throughout my doctoral research, helping me to theorize 'inreach' practice as an artistic device. 'Making strange' has always, in some way or other, been part of the way I experience and express curiosity, model ethics and enact politics. Victor Shklovsky's theory of enstrangement (1919) created a space in my research to think the embodiment of in-betweenness, where ambiguity, uncertainty and humour mingle with the facts, fictions and conventions of engineering as an epistemic and 
technical discipline. My interest in Shklovky's concept lies in its attention to techniques of renewing perception by enlarging our ways of noticing, such as those employed by the writer Tolstoy in his ability to "reach our conscience" not by "calling a thing or event by its name but by describing it as if seen for the first time, as if happening for the first time." ${ }^{15}$ In his essay, Art, as Device, Shklovsky argues that the work of enstrangement activates perceptions of non-identity and affinity coming into relation in the same image or, in the case of my research, poetic communicational space. This approach infuses the glossomatic process, which seeks to generate conditions whereby words reveal their excess materiality and agency in the world, thereby enstranging words in order to stimulate perceptions and "reach our conscience" anew. Shklovsky's understanding of Art as "the means to live through the making of a thing" speaks to the ways art-based and creative research methods can structure and make space for reflection and apperception, and for the production of insight, imagination and knowledge, and for lives "that can be seen, felt, lived tangibly."

On the Ioth of March, 2017, I presented a selection of what I called 'Invarious Vignettes' from my ongoing research to the ATTP. I used a Power Point slideshow, a script and my voice as rhetorical devices. My choice of the word 'invarious' was not accidental but indicated a glossomatic process in action. From my conversations with Prof. Bühlmann I understood this was a concept that stimulated mutual interest, though it was clear our understanding was asymmetrical (Prof. Bühlmann has written extensively on this concept ${ }^{17}$, I had merely overheard it and was intrigued by its poetic and philosophical affordances). By working this word into my presentation title, I was indicating this mutual interest but also signalling the possibility for productive mis-understanding (a glossomatic process is nothing if not risk-taking). The word 'invarious' was selected as a choreographic object to arouse attention, curiosity and critique within the conversational space and duration of the presentation and subsequent discussion. Ultimately, the aim of this narrated Power Point presentation was to invite the ATTP to act as a foil to my research vignettes, thus opening up an atmosphere of enstrangement to elicit interpretation and critique.

\section{RESULTS}

My engagement with the ATTP encouraged me to claim my artistic research practice as both glossomatic and poetic. By presenting 'Invarious Vignettes' on my research to a room of ATTP researchers (approximately

I5 Viktor Shklovsky, 'Art, as Device', trans. by Alexandra Berlina, Poetics Today, 36.3 (2015), 15I-74 https://doi.org/I0.1215/03335372-3160709. I63.

I6 Ibid., I54.

I7 Braidotti and Hlavajova, Posthuman Glossary, (London: Bloomsbury Academic, 2018), 212-216 
twenty people were gathered to listen and respond), I was afforded an opportunity to model and explore my glossomatic process in a different epistemic and technical context. The (previously unpublished) script of my presentation and the transcription of the discussion which followed illustrate the insights and critique generated through this encounter. Therefore, I have edited excerpts of these together (a kind of textual montage) to form a new script. For additional context, I have also included some references from my doctoral thesis. ${ }^{18}$ These excerpts are then organized around three phrases that go towards making a revised glossary of the glossomatic method developed during my doctoral research with CTVR. The excerpts also work as a provisional critique and discussion of glossomatic processes, situating them in a wider philosophical and technical context for further elaboration.

\section{COMMUNICATING COMMUNICATIONS}

FOLEY: She wanted to know how to Communicate Communications - she was pretty confident that the Eameses had nailed it. "Surely," she seemed to say to me, "we can reverse engineer the Eameses film?" I didn't know any better. I said, why not? I've nothing to lose. In 1953, Ray and Charles Eames released $A$ Communications Primer. It was informed by Claude Shannon's I948 paper on information theory, the one, it is often said, that changed the game of telecommunications. She was charmed and inspired by this film and it was this film that brought me into touch with telecommunications research. When I met Prof. Linda Doyle, the Director of CTVR, she wanted to know how Information and Communications Engineers could do engineering through the lens of Architecture. She felt strongly that everyone would benefit.

Inversely, the very reason that Ray and Charles Eames made $A$ Communications Primer was because they believed that architects stood to benefit from knowing about Information Theory (The beginnings of the Smart City). As Charles Eames said: "I had the feeling that in the world of architecture they were going to get nowhere unless the process of information was going to come and enter city planning in general. You could not really anticipate a strategy that would solve the increase in population or the social changes which were going on unless you had some way of handling this information ... so we made a film called A Communications Primer, essentially for architects." ${ }^{\text {I9 }}$

I8 Jessica Foley, 'Inreach: A Choreographic Process of Transversality'

I9 Paul Schrader, 'Poetry of Ideas: The Films of Charles Eames,' Film Quarterly, 23.3 (1970), 2-19 https://doi.org/10.2307/1210376 9. 
While trying to learn how to single-handedly reverse engineer the Eameses work, I got deeply distracted by their earliest film, Blacktop, made in 1952. Finding this film more compelling than the former, I began to 'reverse engineer' or read this film in detail, trying to gain insight on how the Eameses approached filmmaking. It was by reading this film, counting the seconds and registering the movements and flow of each shot, making an account of it, that the theory of phronesis became relevant. According to David H. Fisher, phronesis "disrupts familiar ways of seeing: it disrupts the narcissism of liquid life, inviting a different kind of movement than the restless search for the new, the gratifying, the linked. A conversational movement between figure and ground-figure and the immediate focus of perception, ground as tradition (Gadamer), ground as the polysemic voices of the other (Ricoeur) - becomes a basis for expanded possibilities of judgement and action in the present, responding to the claims of the other." ${ }^{20}$ The Eames's baroque films became choreographic objects for me to work with-objects that 'urged participation' of a different texture within CTVR ... reading their works in this context began to open up the idea of communication and what this could mean for telecommunications research in a place like Dunlop Oriel House (CTVR's building at Trinity College Dublin). This is how CTVR began to work more architectonically, by bringing excessive or surplus-to-requirement things/ideas/artefacts into relation. Through the Eameses and telecommunications research, I was learning how to work intimately and impotently ${ }^{2 \mathrm{I}}$ within this context... and it was in this way that a choreographic process of communicating communications was set in motion through CTVR.

ATTP (VERA BÜHLMANN): What I'm wondering is your ... the notion of sterility, the impotence ... you said several times that your position in this research group was an impotent one?

FOLEY: So this is something I just snuck in, in the past couple of days, and it's something I'm curious about. Because I'm in Vienna I

Gadamer and Ricoeur: Critical Horizons for Contemporary Hermeneutics, ed. by Francis J. Mootz and George H. Taylor, Continuum Studies in Continental Philosophy (New York: Continuum, 2011). 158

2I This word was used as another 'choreographic object', much in the same way 'invarious' was used. It prompted an interesting discussion around the logic of potential, highlighting this an important vector of critique for an Architectonics of Communication. The choice of the word 'impotent' was prompted from listening to the language and reading the texts of the ATTP in the first week I was with them, and linking this with an essay I was concurrently reading by Beatriz Colomina on the architect Adolf Loos. Beatriz Colomina, 'Intimacy and Spectacle: The Interiors of Adolf Loos', AA Files, 20, (Autumn 1990), 5-15. Using the word 'impotency' in relation to Adolf Loos', architectural style was part of a glossomatic process of placing myself while opening up a critique of architectonic method with ATTP. 
was looking at Adolf Loos ... so this [using the word impotency] is just me thinking out loud ... the use of the word impotent and intimacy ... it has to do with comfort. Beatriz Colomina talks about Adolf Loos's architecture, his [interior] spaces, as a combination of intimacy and control. Intimacy and Control equal comfort. ${ }^{22}$ [I was thinking about] the opposite of control-impotent was one of the words that came up-powerlessness-so I'm just playing with that. When I began it was a very asymmetrical group - me and the engineers. I think it's important to acknowledge those power relations and structures.

ATTP (VERA BÜHLMANN): I think it's also interesting because everyone wants potentiality now, potential, potential, potency ... so, we don't want possibilities anymore, we want a kind of material and potential ... and then to say, okay, I'm going to void this, that is to symbolize it in a way, to actually say it's impotency, that's also a very interesting move...

FOLEY: A lot of the time I don't know what the language is doing, but it just seems like it's the right thing, and then it takes forever to try and translate it. And I think in order to translate these things you can't do it on your own, which is also one of the reasons why I'm here. I want to know, if I give you these terms, what do they translate as?

ATTP (LUDGER HOVESTADT): But I think impotency and potency ... you are playing the same game ... I think ... I don't know English language enough ... the same with, it's very sensible and beautiful how you use language, but to get it I really have to check it, look it up ... but impotency, I think you have to get out of the ... I appreciate the vector you are trying but you have to get out of the potency ...

\section{CHOREOGRAPHIC OBJECTS}

ATTP (OLIVER SCHÜRER): What is the Choreographic Object in your work? Could you tell us more about this and its relation to the classical understanding of choreography?

FOLEY: The research I was doing was very opportunistic. It was always about finding things that could help me work in that place (CTVR). The idea of the Choreographic Object came from the choreographer William Forsythe. What I understand by it is that he might use a balloon in a room and he would invite people into the room, and the balloon becomes a choreographic object, it begins to attract people to it or if there are many balloons ... so it's about power and how objects move people. And it's not that

Colomina, 'Intimacy and Spectacle'. 5 . 
the object is necessarily telling you what to do, it's more how ... what's the relationship between the object and the person as they encounter each other? He's conscious of the fact that placing things in space set about certain movements. I think that's what he means by choreography. It's not necessarily prescribed; it's not like a programme or even an algorithm. It's more a possibility. So that's what I liked about it. I used the concept after the fact. I'd be doing the research and then trying to find 'oh, I need language to describe what I'm doing'. Erin Manning's interpretations of Forsythe's concept of the choreographic object describe them as objects that "activate an environment for movement experimentation. The idea is to create an atmosphere that slightly tweaks the time of everyday movement, inviting it to tend toward the time of the event." ${ }^{23}$ For Forsythe, a choreographic object is "an alternative site for the understanding of potential instigation and organization of action" which "would draw an attentive, diverse readership that would eventually understand and, hopefully, champion the innumerable manifestations, old and new, of choreographic thinking." ${ }^{4}$ I perceived a relationship between CTVR's desire to Communicate Communications and the principle of thinking choreographically.

ATTP (OLIVER): This comes close to Social Engineering?

FOLEY: It's a bit unnerving when you put it that way. Well, there's a kind of doubleness in the process, because there's - and this is one of the things about language and trying to figure out how to be more precise with words - because, you feel a little bit like a Demon or a Saint. And it's really terrifying, being always in that feeling. That's how I've been for, you know, seven years. Social Engineering ... I don't think I would ever like to say I'm doing Social Engineering ... that's not the point. It's an ongoing struggle, finding a language that can describe this. Which is why I'm interested in what you (ATTP) are doing. You seem to be using language in a really specific way ...

ATTP (VERA BÜHLMANN): The way that you have described the choreographic object to me sounds so familiar to the quasi-object of (Michel) Serres actually ... this dance you are describing, you feel like a Demon, you evoke some kind of presence in the social space, you do, but you don't cause it. And that's how he describes the communication process... with Serres, instead of thinking about Communication as from a Sender to a Receiver, it's always 
the point of view of the interpreter, so that sendings and receivings are going on - this is the nature of it - and whenever you communicate you are the interceptor, always. And then by intercepting you share your secret ... And then this strange idea of being a kind of medium in this demonic way becomes no more mysterious than when you dig in the ground and water comes out. And also, the way that you use the two-word poems, I didn't understand that before, that's powerful, I think. This is great!

\section{TWO-WORD POEM}

FOLEY: This is an ongoing poetic experiment in my research practice, to make two-word poems that have agency in the world. This is a two-word poem:

Engineering Fictions

It felt like the statement of a problem. When I composed it, I was getting intimate with the research centre and its inhabitants. With my questions about communication, I made people feel at once at ease and uncomfortable. I made myself uncomfortable. I perceived telecommunications engineering as a way of writing the world. I felt, without understanding, it's vast power. But the engineers I worked alongside did not seem to feel as I did: that their work was powerful. For many, it was tedious. Dull. Making the internet go faster. The occupation of 'Engineer' seemed to follow a cliché, as if Engineers were only either the Heroes or Handmaidens to power (the Nation State, the Multinational Corporation, the Private Affluent Person). So, I expanded my two-word poem into a living support structure to begin a sideways investigation - I imagined this poem as a kind of stent that could help increase the flow of thoughtful, playful and critical conversation and literacy within the research centre. And this two-word poem became Engineering Fictions, the writing workshop as a cultural stent ...

ATTP (VERA): So you need the poem in order to have Engineering Fictions, and then it works, you see! Because then you have, either from the Engineering or the Fiction, you have a metrum (a measure), but the metrum is not about measuring precisely, it's about giving some kind of structure where some kind of presence can appear through the words.

FOLEY: And the coining and subsequent improvisation of Engineering Fictions (as a writing workshop), its architectonics if you will, was provoked by three choreographic objects picked up through my hanging around CTVR: The Eamesian concept of 'fictions of reality'; an excerpt from Ludwig von Bertalanffy's General System Theory on the 'verbal model'; and also my own process 
of learning to write fiction through a workshop with the Irish author Pat McCabe. What this two-word poem, this poetry of naming, afforded me was the possibility for a critical and playful 'poetry of ideas' to flow within CTVR. For example, by working with the idea of fiction we begin to think about our assumptions of fact; by thinking about the power of verbal models, we begin to think about the power of mathematical models and we how we come to know the world; by learning to write fiction, becoming attentive to the idea that certain things cannot be taught or cannot be packaged into so-called 'transferable knowledge', we begin to imagine that some knowledges might only be inhabited and experienced, or that certain kinds of knowledges can only emerge over time, like wisdom.

ATTP (OLIVER): The poem aspect would interest me more, what makes these 'Engineering Fictions' into a poem ... and would something like 'Scandalous Scaffolding', for example, also be a poem? What makes one poetic and the other not?

FOLEY: Well, scandalous scaffolding would mean more to you than to me ... I'm creating patterns of meaning, that's what I'm doing ...

ATTP (VERA): To speak to your question, Oliver, about what makes it poetry ... so you could say, it's declaration, what makes it poetry. So you could say it's a title. Or you could say it's a label. But then you tell another story. So the point, I guess, as I understand your work, and that's the subtlety I see in it, is that words alone don't say it ... but they are themselves like a choreographic object. And then they are familiar enough to engage people, so it's not some esoteric secrecy language. But it doesn't try to be neutral, it doesn't try to claim a presence on its own. And I think this is very much the heart of poetry, to look at words like that. Because you don't really have an author, for example. So the poet is not the author of his poetry, he is giving form to a kind of inspiration, that's still, that's why poetry and lyrics are so important to give form to a soul, and soul is not a literal thing. As long as it takes on some kind of communicative presence. So this is the context of poetry since antiquity. It's older than drama and all of that. So it's, yes, by declaration I would say. And that's what's interesting, also, because in (computer) programming we have these two paradigms, these two main paradigms: declarative programming and instructional programming.

\section{DISCUSSION}

I began this essay by acknowledging a strain in my voice, a difficulty in moving beyond the style of the 'modest witness' espoused for so long (albeit attenuating) by scientific and technical disciplines like engineering. 
To write in the first person, with the critical and enlarged 'I' of methods like participant observation and autofiction, remains a challenge. Arguably, this is a challenge facing all those whose modes of inquiry slip and move in between formal and established disciplines and seek to at once embody and express creative intellectual endeavour. Underlying such endeavours repeals the adage espoused by arts educator Corita Kent and conceptual artist John Cage: "You cannot create and analyse at the same time. They are different processes." ${ }^{25}$ Glossomatic processes are those that accept this adage and yet continue to push and pull against its constraints. Such inquisitive and critical processes, as outlined above, are doomed to strangulation if they refuse (or are rendered unable) to accept that voice, word and movement are key devices in its method.

The very idea of a 'glossomatic' process was unavailable to me prior to writing this essay. This in itself is an indication of a glossomatic process at work, where voice and word intercept a context, opening up another channel for communication and theory to emerge as part of a larger pattern. Prof. Bühlmann contextualizes such processes in relation to Michel Serres work on the 'quasi-object' when she says, "whenever you communicate you are the interceptor, always. And then by intercepting you share your secret...." Continuing with Prof. Bühlmann's thinking, a glossomatic process is such that offers, "some kind of structure where some kind of presence can appear through the words." These reflections are instantiations of the generous act of foiling that comes with glossomatic processes, whereby an ethics is summoned through the declaration of specific words in context with other listening bodies. This is what the poet Séamas Heaney highlights as part of poetry's power as a method of "offering consciousness a chance to recognize its predicaments, foreknow its capacities and rehearse its comebacks in all kinds of venturesome ways." ${ }^{26}$ Such poetic effects are tangible in the transcripts from my conversation with the ATTP, in our discussion of what constitutes a poem and in the opening up of a critique around the logic of potential. Where and when such critiques move next remains unprescribed.

25 For an overview of this adage visit https://www.brainpickings.org/2012/o8/10/1orules-for-students-and-teachers-john-cage-corita-kent/ [Accessed 31.10.18]

26 Séamas Heaney, The Redress of Poetry: Oxford Lectures (London and Boston: Faber and Faber, 1995), 2. 
